Fat Mass\% (FM,\%), Lean Mass (LM, kg), Bone Mineral Content (BMC, mg), and Fat Mass Index (FMI: trunk fat mass/legs fat mass). Statistics. Mean \pm SD, ANOVA, Scheffe's F procedure for post-hoc comparison.

Results Lean Mass was the same in the 4 groups. Despite 43 months of disease duration, Naive and Controls had the same fat mass, BMC and FMI. The two treated HIV-infected groups had lower Fat Mass and upper Fat Mass Index than Controls. Loss in Fat Mass at the expense of the legs was proportional to duration of HAART. The great variability of the FMI (SD) in these two groups suggested a poor clinical sensitivity to change. Decrease of BMC seemed treatment-dependent. Lipodystrophy appeared also age-related.

\begin{tabular}{|c|c|c|c|c|c|}
\hline & BMI & BMC & $\begin{array}{l}\text { Lean } \\
\text { mass }\end{array}$ & $\begin{array}{l}\text { Fat } \\
\text { mass }\end{array}$ & Fat mass index \\
\hline Controls (1) & 25 & 3197 & 58.7 & 16.1 & $2.04 \pm 0.43$ \\
\hline Naive (2) & 25 & 3061 & 61.2 & 12.4 & $2.07 \pm 0.38$ \\
\hline n-CLD (3) & 23 & 2859 & 58.8 & 9.8 & $2.49 \pm 0.90$ \\
\hline CLD (4) & 23 & 2700 & 57.6 & 9.3 & $3.46 \pm 1.10$ \\
\hline ANOVA & $\begin{array}{l}\mathrm{P}< \\
0.05\end{array}$ & $P<0.05$ & n.s. & $P<0.05$ & $P<0.05$ \\
\hline $\begin{array}{l}\text { Scheffe }(P< \\
0.05)\end{array}$ & $\begin{array}{l}1-4,2- \\
4\end{array}$ & $\begin{array}{l}1-3,1-4,2- \\
4\end{array}$ & n.s. & $1-3,1-4$ & $\begin{array}{l}1-3,1-4,2-4,3- \\
4\end{array}$ \\
\hline
\end{tabular}

Conclusion DEXA allows an early diagnosis of fat maldistribution. We propose to perform this exam to all HIV-infected patients once a year before treatment and every 6 months in patients under treatment.

\section{SAT0223 LYME MENINGORADICULITIS IN AN ENDEMIC ZONE: CLINICAL SIGNS}

${ }^{1} \mathrm{~F}$ Roux, ${ }^{2} \mathrm{~L}$ Artru, ${ }^{2} \mathrm{~B}$ Haettich, ${ }^{2} \mathrm{~J}$ Esparbes, ${ }^{2} \mathrm{X}$ Puéchal. ${ }^{1}$ Rheumatology, Hospital Bichat, Paris; ${ }^{2}$ Rheumatology, Le Mans General Hospital, Le Mans, France

\subsection{6/annrheumdis-2001.726}

Background Neuroborreliosis has been called "the new great imitator".

Objectives The aim of this study was to define the symptoms of meningoradiculitis.

Methods We collected prospective data from all patients admitted to hospital with Lyme meningoradiculitis between June 1st, 1998 and December 31st, 1999 in an endemic zone located in western France. Diagnosis was based on lymphocytic meningitis associated with either intrathecal specific antibody synthesis or high serum titers of specific IgM in ELISA and western Blot analysis.

Results Eleven patients ( 9 women, 2 men), with a mean age of 62 years (range: 37 to 87 ) were included during the study period. Two thirds of these patients were admitted to rheumatology wards during the summer. The onset of symptoms was preceded, 5 to 60 days earlier, by a tick bite in $64 \%$ of cases or erythema migrans in $55 \%$ of cases. In $18 \%$ of patients, neither a tick bite nor erythema was observed. Non specific symptoms were recorded in $82 \%$ of cases, with transient fever or flu syndrome in $45 \%$ of all cases. Cervical radiculoneuritis was observed in 4 cases, symptoms affecting several nerve roots of the lower limbs in 3 cases, femoral neuropathy in 2 cases, a bilateral sensory radiculoneuritis T11-12 in one case and poorly localised paresthesias in the lower limbs in one case. The meningeal signs and symptoms were minimal or, more frequently, absent. A peripheral motor paresis was observed in one quarter of the cases, but without Bell's palsy or encephalic or medullary signs. In half the patients, there was associated spinal pain not relieved by rest. All patients reported nocturnal exacerbation in pain. The electrocardiographic abnormalities included firstdegree atrioventricular block in 2 patients. The course of the disease was consistently favourable on ceftriaxone IV treatment, with rapid effective relief of pain.

Conclusion A diagnosis of Lyme meningoradiculitis should be considered in endemic zones in all cases of spine pain and/or radiculitis with nocturnal exacerbation, especially in the summer period.

\section{SAT0224 PERIPHERAL NERVE INVOLVEMENT IN HCV-INFECTED PATIENTS WITH AND WITHOUT MIXED CRYOGLOBULINEMIA}

${ }^{1} S$ Sampaolo, ${ }^{2} \mathrm{~L}$ Ambrosone, ${ }^{1} \mathrm{G}$ Sanges, ${ }^{1} \mathrm{~L}$ De Martino, ${ }^{2} \mathrm{~S}$ Migliaresi, ${ }^{1} \mathrm{G}$ Di lorio, ${ }^{2} \mathrm{G}$ Valentini. ${ }^{1}$ Neurology Unit; ${ }^{2}$ Rheumatology Unit, Second University of Naples, Naples, Italy

10.1136/annrheumdis-2001.727

Background In contrast to cutaneous vasculitis, the morphology of which is well known, that of peripheral nerve lesions in HCV-positive mixed cryoglobulinemia (MC) patients are still under debate. ${ }^{1,2}$

Objectives To evaluate the pathological processes underlying the peripheral nerve damage in HCV-infected patients, with and without MC.

Methods From $14 \mathrm{HCV}$-infected patients (10 with MC and 4 without), all with clinically peripheral neuropathy, a sural nerve biopsy was obtained. Diseases other than HCV infection were excluded. The tissue samples were processed according to standard methods to perform morphologic and morphometric evaluation, on light and electronmicroscopic study. An immunohistochemical evaluation was carried out using labelled antisera against immunoglobulins (IgA, IgG, IgM), complement proteins (C1q, C3, terminal complex C5-9), and cellular antigens (CD3, CD11a-b-c, CD20, CD45, CD68).

Results In all nerve biopsies an axonal involvement without a distinctive vasculitis was found. Scarce perivascular infiltration by monuclear cells was observed, particularly around perineural blood vessels; extravasation of red cells was also found in the endoneurial vessels. Immunohistochemical study pointed out deposits of immunoglobulins and complement in sub-perineurial vessels, and infiltrations by mononuclear cells, mainly macrophages and CD4 $\mathrm{T}$ cells. Demyelinating neuropathy was only observed in patients without MC.

Conclusion Our data suggest that in $\mathrm{HCV}$-infected patients different physiopathological processes are involved in induction of peripheral nerve damage. A potential direct pathogenic role of HCV should be investigated.

\section{REFERENCES}

1 Bonetti B et al. J Neuroimmunol. 1997:73:145

2 Bonetti B, et al. Virchows Arch. 1999;434:533 